\title{
Lactation yield: Interval level comparison of milk records for genetic improvement in Friesian vs Arsi crossbred cows in the highlands of south eastern Ethiopia
}

\author{
Oumar Wabe ${ }^{1}$ and Kassahun Asmare ${ }^{2}$ \\ ${ }^{1}$ Allage Agricultural Technical, Vocational Education Training College, P.O. Box 077 \\ ${ }^{2}$ School of Veterinary Medicine, Hawssa University, P.O. Box 005
}

\begin{abstract}
Milk recording intervals was studied by analysing 1220 lactation records of Friesian $\mathrm{x}$ Arsi crossbred cows kept in south eastern highlands of Ethiopia. Milk Recording Intervals (MRI) comparison was made at 15, 30 and 45 day's length. Accuracy was measured in terms of percentage difference between actual and estimated yield, Root Mean Square Error (RMSE) and coefficient of determination $\left(\mathbf{R}^{2}\right)$. The study revealed that 15, 30 and 45-day MRI can estimate lactation yield accurately to extent of less than five percent error. Lactation yield estimated by 15-day MRI was marginally more accurate with higher $\mathrm{R}^{2}(99.6 \%)$ and lower RMSE (34.8) values compared to 30 and 45-day MRI. Simple regression analysis indicated that yield of $9^{\text {th }}$ period (121-135 days) in 15-day; the $5^{\text {th }}$ period (121-150 days) in 30-day and the $3^{\text {rd }}$ period (91-135) in 45-day time interval provided reliable estimate of 305-day yield. The step-wise regression analysis showed that combination of more than three records did not result in increasing the accuracy of estimates. Thus 30 and 45-day MRI can be used in the estimation of lactation yield in Friesian $\mathbf{x}$ Arsi crossbred cows.
\end{abstract}

Keywords: Accuracy, Lactation yield, Interval comparison, Test day http://dx.doi.org/10.4314/evj.v19i2.7

\section{Introduction}

Milk recording has been playing an important role in countries with an advanced dairy industry. In many developed countries well over 50 percent of dairy cows are involved in recording scheme. Data from well-organized, properly executed milk recording schemes facilitates better herd management and planning, and enables farmers to produce milk more economically. Furthermore, milk recording enables the accurate identification of genetically superior animals for selection, through genetic evaluation (Silvestre et al., 2006; Jeretina et al., 2013). Despite its enormous benefits, milk recording has not been adopted in many Sub-Saharan African countries. Only a small proportion of the dairy 
cows have complete production information (Wasike et al., 2011). This is partly attributed to lack of awareness, low educational level and lack of incentives for participation in milk recording. These factors limited the availability of milk yield data in most part of the developing world where Ethiopia is a case in point. Thus such scenario calls up on the need to optimise the contribution of each collected record to the genetic evaluation process (Bajwa et al., 2002). In this regard reviewing studies mainly made in Europe and North America have shown that recording milk every two months is accurate enough for progeny testing. From genetic improvement point of view, monthly recording was reported to be accurate enough for the purpose of culling and selection as well (MacDaniel, 1969; Syrstad, 1993; McGill et al., 2014). In the background of these facts, the test-day models have been suggested as the method of choice for the analysis of milk yield traits in order to maximize the use of all available information. This method becomes even more important in countries with smaller herd size and without well-established milk recording schemes (Bilal and Khan, 2009).

Since the culture and practice of record keeping in our dairy system is reportedly weak, such possibilities are great opportunities to unveil the genetic performance of dairy cattle based on the available data. Nevertheless, it is essential to find a compromise between the best interval and the one that is practical and, yet; does not sacrifice accuracy. This study was therefore aimed at determining the most appropriate interval for milk recording that could be of use in making proficient breeding-management decision with a view of increasing the overall efficiency of dairy enterprise.

\section{Materials and methods}

\section{Study area}

The Agarafa technical and vocational training centre is located at a distance of about $460 \mathrm{~km}$ south east of Addis Ababa. It is situated at $38^{\circ} 40^{1} \mathrm{E}$, longitude and $4^{\circ} 11^{\prime} \mathrm{N}$, latitude and has an altitude of 2350 meter above .sea .level. The annual temperature ranges from a minimum of $5.5^{\circ} \mathrm{C}$ to $8.7^{\circ} \mathrm{C}$ to the maximum of $17.5{ }^{\circ} \mathrm{C}$ to $32{ }^{\circ} \mathrm{C}$. The mean annual rainfall varies from $800 \mathrm{~mm}$ to $1000 \mathrm{~mm}$. The rainy seasons is bimodal and consisted of the short rainy season that extended from March to June, the long rainy season, which extended from July to October, and the dry season that extended from November to February. 


\section{Study design}

This is a retrospective study made based on the milk record data available at Agarfa multipurpose agricultural development agents training centre. The data was compiled over 19 years (1982-2001). In the farm hand milking was done twice daily, early in the morning and late in the afternoon in the milking parlour. The volume of milk produced (litre) by each cow was measured immediately after each milking and recorded. Daily milk production of individual cow was the sum of the morning and the evening milking. As a part of routine practice, dates on which milking started and dry-off were also recorded. Parity of cows was classified from 1 to 5 and the last category had some cows that were in the $6^{\text {th }}$ and $7^{\text {th }}$ lactation, hence designated as $5^{+}$parity.

\section{Study animals}

The dairy herd consisted of 50, 75 and 87.5 percent Friesian graded animals. Animals are kept in the semi-intensive management system where supplementation of balanced ration effected to lactating cows to supplement the natural foraging out in the field.

\section{Data management and analysis}

\section{Data structure}

A total of 1,220 lactation records consisting of 668,471 , and 81 records belonging to 50, 75 and 87.5 percent Friesian $x$ Arsi crossbred cows, respectively, were used to create the database. Daily milk yield for missing days were estimated using linear interpolation of yields reported for a day before or after the missing days. Lactations with interruption of two consecutive days at any stage of lactations were not considered. The $5^{\text {th }}$ day after calving was taken as the start of lactation and the period was considered to have ended when a cow was no longer milked twice a day. Lactation length of 210 days was taken as a lower limit. Thus out of the total 1,220 records, 1,111 records had complete 305 days lactation length.

\section{Milk recording intervals and calculation of test day yields}

Milk Recording Interval (MRI) of $30 \pm 4$ days was considered as a standard and compared with $15 \pm 4$ days MRI and $45 \pm 4$ days MRI. In the 15-day interval there were 20-test day record for each cow, 10 in the monthly recording, and 
7 in the 45- day interval recording (Table 1). Milk yield for each test period was calculated for each cow as per the methods described by Gravert (1987). The method involves taking the average of the previous and current test yield, which was then multiplied by the number of days in the interval. The sum of yield of each period formed the estimated lactation yield for various milk recording intervals. Thus, estimated lactation yield was sum of the 20,10 and 7 test periods for 15-day MRI, 30-day MRI and for 45-day MRI, respectively.

Table 1: Test period numbers and corresponding intervals in the three milkrecording plans.

\begin{tabular}{llll}
\hline \multicolumn{4}{c}{ Milk recording Intervals } \\
\hline $\begin{array}{l}\text { Test period } \\
\text { number }\end{array}$ & 15 -day MRI & 30-day MRI & 45-day MRI \\
\hline 1 & $1-15$ & $1-30$ & $1-45$ \\
2 & $16-30$ & $31-60$ & $46-90$ \\
3 & $31-45$ & $61-90$ & $91-135$ \\
4 & $45-60$ & $91-120$ & $136-180$ \\
5 & $61-75$ & $121-150$ & $181-225$ \\
6 & $76-90$ & $151-180$ & $226-270$ \\
7 & $91-105$ & $181-210$ & $271-300$ \\
8 & $106-120$ & $211-240$ & \\
9 & $121-135$ & $241-270$ & \\
10 & $136-150$ & $271-300$ & \\
11 & $151-165$ & & \\
12 & $166-180$ & & \\
13 & $181-195$ & & \\
14 & $196-210$ & & \\
15 & $211-225$ & & \\
16 & $226-240$ & & \\
17 & $241-255$ & & \\
18 & $256-270$ & & \\
19 & $271-285$ & & \\
20 & $286-300$ & & \\
\hline
\end{tabular}

\section{Measurement of accuracy}

Percentage difference, which is absolute difference (ignoring the signs) between actual measured milk and estimated milk yield, expressed as a proportion of actual milk yield were calculated from each of the MRI. Percentage data was log transformed and thereafter analysed using general linear models procedure (GLM) of SAS (SAS, 2000). Fixed effects included in the model were genetic group, season of calving and parity as indicated in the following model: 


$$
\mathrm{Y}_{\mathrm{ijkl}}=\mu+\mathrm{G}_{\mathrm{i}}+\mathrm{S}_{\mathrm{j}}+\mathrm{P}_{\mathrm{k}}+\mathrm{e}_{\mathrm{ijk} \mathrm{l}}(\operatorname{model} 1)
$$

Where, $Y_{i j k l}$ is percentage difference for $i^{\text {th }}$ genetic group, $j^{\text {th }}$ season of calving and $\mathrm{k}^{\text {th }}$ parity; $\mu$ is the general mean; $\mathrm{G}_{\mathrm{i} \text { is }}$ genetic group $1-3(50 \%, 75 \%$ and $87.5 \%$ Friesian grade); $\mathrm{S}_{\mathrm{j}}$ is season of calving 1-3 (short rainy season, long rainy season and dry season; $\mathrm{P}_{\mathrm{k}}$ is parity group 1 -

$5^{\text {th }}\left(1,2,3,4,5^{+}\right.$lactations $)$and eijkl is the random residual effect.

\section{Relationship between actual and estimated lactation yield} Relationship between estimated lactation milk yield (from test day yields) and actual lactation milk yield was studied for the three recording intervals using simple linear regression as per the following model:

$$
\hat{\mathrm{Y}}_{\mathrm{j}}=\mathrm{a}_{\mathrm{i}}+\mathrm{b}_{\mathrm{i}} \mathrm{X}_{\mathrm{i}}+\mathrm{e}_{\mathrm{ij}}(\text { model 2) }
$$

Where, $\hat{Y}_{j}$ is estimated yield of $j^{\text {th }}$ record; $a_{i}$ is the intercept for $i^{\text {th }}$ period actual yield; $b_{i}$ is the regression coefficient of $Y$ on $i^{\text {th }}$ period actual yield; $X_{i}$ is the $i^{\text {th }}$ period actual yield and eij is the residual random error associated with the $i^{\text {th }}$ period actual yield of $j^{\text {th }}$ record.

\section{Identification of single or combinations of actual records that best estimate lactation yield}

Stepwise regression analysis, as described by Draper and Smith (1981) was followed where relative contribution of each additional variable in the multiple regressions is tested before it is selected for next step. This was achieved by using the $\mathrm{R}^{2}$ improvement method of SAS (2000). The model used was:

$$
\begin{aligned}
& \hat{\mathrm{Y}} \mathbf{j}=a_{k}+\sum_{i=1}^{k}\left(b_{i} \mathrm{X}_{i j}\right)+\mathbf{e}_{\mathrm{ij}} \\
& \hat{\mathrm{Y}}_{\mathrm{j}}=\mathrm{a}_{\mathrm{k}}+\sum_{\mathrm{i}=1}^{\mathrm{k}} \mathrm{b}_{\mathrm{i}} \mathrm{X}_{\mathrm{ij}}+\mathrm{e}_{\mathrm{ij}}
\end{aligned}
$$$$
\text { (model 3) }
$$

Where, $\hat{Y}_{j}$ is estimated yield of $j^{\text {th }}$ record; $X_{i j}$ is observed actual yield of $i^{\text {th }}$ period of $j^{\text {th }}$ record; $\Sigma b_{i}$ is sum of partial regression coefficients of $Y$ on trait $X_{i ;} a_{k}$ is the specific intercept when there are $k$ independent variables in the equation and $e_{i j}$ is the residual random error associated with the $i^{\text {th }}$ period actual yield of $j^{\text {th }}$ record. 


\section{Results}

\section{Actual and estimated lactation milk yield}

The overall mean lactation yield for all genotypes was $1969.9 \pm 16.1$ litres. Lactation yields of the three genotypes i.e. $50 \%, 75 \%$ and $87.5 \%$ ( Friesian $\mathrm{x}$ Arsi) crosses were 1892, 2065, and 2056 litres, respectively, which was not statistically significant $(p>0.05)$. The estimated milk yields based on cumulative of test day yield measured by MRI of 15, 30 and 45-day was 1965, 1971, and 1959 litres respectively, and these values are close to lactation milk yield obtained from the sum of actual daily milk records.

\section{Percentage differences}

The mean percentage difference were $1.42 \pm 0.04,2.44 \pm 0.06$ and $3.16 \pm 0.08$ for the 15-day, 30-day and 45-day MRI respectively, for all genetic groups investigated. It could be noted that as the interval between milk recordings increased, percentage differences also increased. Nevertheless, the mean percentage of difference in all the three plan of recording of the present study was less than five percent, indicating close agreement between the actual and estimated lactation milk yield.

\section{Factors influencing percentage differences}

Effects of different factors viz, genetic group, season of calving and parity on the three milk-recoding intervals were studied. Neither genetic group nor parity exerted a significant effect $(p>0.05)$ indicating that any of the MRI considered in this study can be equally used for crossbreds of varying exotic blood level of any parity. On the other hand, season of calving had a highly significant effect $(p<0.001)$ in case of 15 -day MRI (Table 2) but not on the other intervals. Percentage difference for cows calving in long rainy season was significantly less $(1.26 \%)$ compared to those cows calving during the short rainy season $(1.55 \%)$ and dry season $(1.47 \%)$. 
Table 2: Analysis of variance for fixed effects on percentage difference estimated by various milk recording interval

\begin{tabular}{lllll}
\hline Source & DF & \multicolumn{3}{c}{ Mean Squares } \\
\cline { 3 - 5 } & & 15-Day MRI & 30-Day MRI & 45-Day MRI \\
\hline Genetic group & 2 & 0.078 & 0.022 & 0.161 \\
Season & 2 & $0.271^{\star * *}$ & 0.003 & 0.009 \\
Parity & 4 & 0.085 & 0.134 & 0.092 \\
Error & 1211 & 0.038 & 0.061 & 0.075 \\
\hline
\end{tabular}

*** Significant at $\mathbf{P} \leq 0.001$

\section{Comparison of accuracy of various interval lengths}

As shown in Table 3, the coefficient of determination $\left(\mathrm{R}^{2}\right)$ which is a measure of prediction accuracy was in range from 98.06 to 99.62 . For the three recording intervals considered, values for $\mathrm{R}^{2}$ were extremely high. The root mean square error (RMSE) for 15, 30 and 45-days of recording interval were 34.8, 62.6 and 79.4 , respectively.

Table 3: Prediction equation of total lactation milk yield from estimates of various intervals.

\begin{tabular}{llll}
\hline & Equations & R2 (\%) & REMS \\
\hline 15 - Day Interval & $\mathrm{Y}=-8.58+\mathrm{x}$ & 99.6 & 34.8 \\
30 - Day Interval & $\mathrm{Y}=-1.57+\mathrm{x}$ & 98.8 & 62.6 \\
45 - Day Interval & $\mathrm{Y}=-13.6+\mathrm{x}$ & 99.6 & 79.4 \\
\hline
\end{tabular}

$\mathrm{Y}=$ estimated lactation milk yield, $\mathrm{x}=$ interval yield

\section{Relationship between estimated and actual lactation yield}

The relationship between estimated milk yields using the three MRI to the actual lactation yield was examined using regression analysis. The analysis revealed that all regression coefficients of the three methods were highly significant $(p<0.001)$. As depicted on the equations developed (Table 3 ), the slope of regression lines is almost unity. Thus, test day yields can estimate lactation yield with a high degree of accuracy. Even recording interval of 45 days gave a reasonable degree of accuracy although RMSE has more than doubled as compared with RMSE at 15 days interval.

\section{Identification of single or combination of effective test periods}

In circumstances where regular recording intervals cannot be implemented, identification of a single record or combination of few records that best estimate lactation yield would be of great value. In the simple regression analysis, the 
$9^{\text {th }}$ test period (corresponding to $121-135$ days interval) in the 15 day MRI; the $5^{\text {th }}$ test period (corresponding to 121-150 days interval) in 30-day MRI, and the $3^{\text {rd }}$ test period (corresponding to $91-135$ days interval) in the 45 day MRI had the highest coefficient of determination and the regression coefficient is associated with small standard error. It could be noted that in all the three intervals, milk measurement taken in the $3^{\text {rd }}$ or $4^{\text {th }}$ month of lactation (90 to 150 days in milk) is the best predictor of lactation yield.

In order to increase the accuracy of estimated yield, various combinations of two, three, four, five and six test periods were considered for each of the three intervals. Considering the actual milk yield for the test period, step-wise regression procedure was followed for identification of efficient period based on the highest $\mathrm{R}^{2}$ value step by step. Periods of recording that gave the maximum $\mathrm{R}^{2}$ for each of the MRI is given in Table 4. For 15-day MRI, combination of yield of period 3 and period 15 gave $R^{2}$ value of 95.0 , which was 7.1 percent more than the $R^{2}$ value obtained for single recording period (Period 9). Inclusion of the $3^{\text {rd }}$ recoding increased $\mathrm{R}^{2}$ by $2.7 \%$ over the combination of two periods of recording. Similar trend and magnitude of improvement in $\mathrm{R}^{2}$ was observed for 30-day and 45-day MRI when yield is estimated using combinations of two periods rather than a single period. In all the three plans of recording, the results showed that there was a continuous increase in $\mathrm{R}^{2}$ values with introduction of yield of new period.

Table 4: Predictive equations with single or combinations of test periods for the different recording intervals and measures of accuracy

\begin{tabular}{llll}
\hline $\begin{array}{l}\text { Combinations of records and } \\
\text { corresponding periods }\end{array}$ & Equations & R2 (\%) & REMS \\
\hline 15 day MRI & & \\
Single record (period 9) & $\mathrm{Y}=281.31+16 \times 1$ & 88.7 & 183.8 \\
Two records (period 3,15) & $\mathrm{Y}=131.9+10 \times 1+11 \times 2$ & 95.0 & 116.5 \\
Three records (period 3,9,15) & $\mathrm{Y}=93.6+4.9 \times 1+5.7 \times 2+7.7 \times 3$ & 97.5 & 83.5 \\
30-day MRI & & & \\
Singe record (period 5) & $\mathrm{Y}=263.1+8.3 \times 1$ & 89.3 & 145.3 \\
Two records (period 2,8) & $\mathrm{Y}=2118.0+3.7 \times 1+5.7 \times 2$ & 95.9 & 117.9 \\
Three records (2,5,8) & $\mathrm{Y}=78.9+2.6 \times 1+3.0 \times 2+3.9 \times 3$ & 98.1 & 78.9 \\
45 day MRI & & & \\
Single record (period 3) & $\mathrm{Y}=2159+5.30 \times 1$ & 90.2 & 171.0 \\
Two records (period 2,8) & $\mathrm{Y}=98.7+2.6 \times 1+3.5 \times 2$ & 97.0 & 94.5 \\
Three records (period 1,3,6) & $\mathrm{Y}=19.2+1.3 \times 1+2 \times 2+2.6 \times 33$ & 98.7 & 63.0 \\
\hline
\end{tabular}

MRI = Milk Recoding Interval; REMS $=$ Root Error Mean Square

$\mathrm{Y}=$ Estimated total lactation yield; $\mathrm{x}_{\mathrm{i}}=$ test day milk yield in 


\section{Discussion}

In this study there was no significant difference in milk yield despite the noted genetic variation. Perhaps this could be due to similarity in management level irrespective of their inheritance i.e. environmental factors such as inadequate feed, poor management system that does not commensurate with the physiological demands of higher grades might have put a limit to the full expression of the genetic potential. In this regard, Wasike et al. (2011) stated that the environmental factors alter the genetic potential efficiency of milkproducing animals and shape of their lactation curves. The average lactation yield obtained in present study was within the range of the reports of total lactation yield for Friesian $\mathrm{x}$ Arsi crosses reported earlier in different places and years (Schaar et al., 1981; Kiwuwa et al., 1983).

The mean percentage difference reported for 15-day, 30-day and 45-day MRI was seen to increase and the standard errors observed in all the three intervals were found to be less than 2.8 percent. Analogues to present result, Gantner et al. (2008) compared milk recording plan at 4-week and 6-week intervals to estimate lactation yield, and found 4 -week interval provides low bias and high accuracy of prediction compared with 6-week intervals. Hence the presence of few errors that exceed five percent in our study agrees with the result of McDaniel (1969) who indicated that 95 percent of estimated lactation milk yields from monthly interval were within \pm 5 percent of the true mean. Other studies done on milk records of pure bred Friesian in different parts of the world also found that lactation estimates based on longer recording interval resulted in greater absolute error and concluded that higher precision is related to the lower interval of recording (Chagunda, 2000; Gantner et al., 2008; Wasike et al., 2011) .

In this study, neither genetic group nor parity exerted a significant effect $(p>0.05)$ on milk recording intervals, indicating that any of the MRI considered in this study can be equally used for crossbreds of varying exotic blood level of any parity. However, estimation of milk yield of cows calving in the long rainy season is more accurate based on 15-day MRI compared to estimates of short rainy and dry season clavers. In recent years, the short rainy seasons in the highlands of Ethiopia have become more variable, and the high percentage difference observed in this particular season could be attributed to this variation. Moreover, it has to be recognized that the 15-day interval method has higher number of test days (test period credits) within a given season than rest of the two methods and likely to be more sensitive in partitioning the source of variance. 
This study has also accounted the expectations that yield in the middle of lactation is less influenced by the shape of lactation curve than is yield either at the beginning or end of lactation period. Similarly, Ibrahim et al. (2003) stated the heritability estimates for lactation yields in the mid-lactation have been either the same or slightly lower than those for 305-day yields, although estimates were lower for the beginning and end of lactation. Furthermore, Kokate et al. (2014) observed higher estimates of accuracy of prediction in the middle portion of lactation in bimonthly test day milk yields.

The step-wise regression procedure which was used to assess the accuracy estimate of the three specified milk record interval along with increased frequency of test periods showed remarkable improvement in all cases. Similar trend and magnitude of improvement in $\mathrm{R}^{2}$ was observed for 30-day and 45-day MRI when yield is estimated using combinations of two periods rather than a single period. The finding of this study strengthens the findings of Syrstad (1993) who argued that even one recording could be of immense value in areas where milk-recording scheme does not exist. Thus "we do not have to be the best to be the enemy of good".

In the light of the poor record keeping practice we have, the finding of interval level comparison of lactation yield is of enormous relevance for performance based genetic selection. However, the data need to be organized at 15, 30 or 45 days interval for respective reasonable accuracy. Moreover, combinations of measurements taken during the course of lactation revealed that at most three measurements could predict total lactation yield accurately, indicating the value of few estimate in circumstances where complete milk recording is not feasible.

\section{References}

Bajwa, I.R., Khan, M.S., Ahmad, Z. and Gondal, K.Z., 2002. Genetic parameters of lactation milk yield as affected by lactation length adjustment procedures. In Proceedings of the $7^{\text {th }}$ World Congress on Genetics Applied to Livestock Production 19-23 August 2002; Montpellier, France. 1-56.

Bilal, G. and Khan, M.S., 2009. Use of test-day milk yield for genetic evaluation in dairy cattle: a review. Pakistan Vet. J., 29 (1), 35-41.

Chagunda, M. G. G., 2000. Genetic evaluation of the performance of Friesian cattle on large-scale dairy farm in Malawi. PhD. Thesis. Georg-August-University of Gottingen, Germany. 
Draper, N. R. and Smith, H., 1981. Applied Regression Analysis. John Willey and Sons, Inc. New York.

Flank, W. and Winnicki, S., 1993. Evaluation of cows on the basis of milk recording one day or several days per month. Anim. Breed. Abstr. 42, 4193.

Flank, W., Winnicki, S. and Zieciak, H., 1995. Variation in yield and composition of milk in consecutive days of milking and its effect on the accuracy of evaluation of milk capacity in cows. Anim. Breed. Abstr. 44, 52.

Gantner, V., Jovanovac, S., Raguž N., Klopčič M., and Solić, D., 2008. Prediction of lactation milk yield using various milk recording methods. Biotechnol. Anim Husb, 24 (3-4), 9-18.

Gravert, H. O. (ed), 1987. Dairy Cattle Production. World Animal Science. . Production System Approach. Elsevier Science publishers. Amsterdam.

Gaur, G. K., Kumar, S. and Pandy, H. S., 2000. Screening of most effective week and month in order to estimate total lactation milk in Murrah buffaloes. J. Appl. Anim. Res. 17, 262-272.

Ibrahim, K., Yavuz A., and Uzmay, C., 2003. Estimation of breeding values for dairy cattle using test-day milk yields. Turk. J. Vet. Anim. Sci. 27, 459-464.

Jeretina, J., Babnik, D., and Škorjanc, D., 2013. Modelling lactation curve standards for test-day milk yield in Holstein, Brown Swiss and Simmental cows. J. anim. plant sci. 23 (3), 754-762.

Kiwuwa, G. H., Traic, J. C. M., Kurtu, M. Y., Getachew, W., Anderson, F. M. and Duckin, J., 1983. Crossbred dairy cattle productivity in Arsi region, Ethiopia. ILCA, Research Reports No. 11. International Livestock Centre for Africa. Addis Ababa.

Kokate, L.S., Singh, A., Banu, R., Gandhi, R.S., Chakravarty, A.K., Gupta, A.K. and Sachdeva, G.K., 2014. Prediction of 305-day lactation milk yield based on bimonthly test day values in Karan Fries cattle. Indian J. Anim. Res., 48 (2), 103-105.

Lindstrom, U. S., 1976. Studies on milk records from Kenya. Accuracy of milk recording with various intervals. Anim. Bred. Abstr. 93,146-155.

McDaniel, B. T., 1969. Accuracy of sampling procedures for estimating lactation yields. J. Anim. Sci., 52, 1742-1761.

McGill, D.M, Peter, C.T., Herman A.M. and Jan J. L., 2014. Strategic test-day recording regimes to estimate lactation yield in tropical dairy animals. Genet. Sel. Evol. 46 (78), 1-13.

SAS. 2000. Statistical Analysis System Institute Inc., Kary, NC. USA. 
Schaar, J., Brannang, E. and Meskel, L. B., 1981. Breeding activity of Ethio-Swidish integrated rural development project; Part II milk production of zebu and crossbred cattle. Anim. Rev. 31, 31-36.

Silvestre, A.M., Petim-Batista, F., and Colaco, J., 2006. The accuracy of seven mathematical functions in modelling dairy cattle lactation curves based on testday records from varying sample schemes. J. Dairy Sci. 89, 1813-1821.

Syrstad, O., 1993. Simple and cheap milk-recording scheme. Proceedings of Tanzanian Society of Animal Production Vol, 20, 232-235.

Wasike, C. B., Kahi A. K. and Peters, K. J., 2011. Modelling of lactation curves of dairy cows based on monthly test day milk yield records under inconsistent milk recording scenarios. Animal. 5 (11), 1780-1790.

Zumbach B. and Peters K.J., 2002. Sustainable breeding programs for smallholder diary production in the tropics. World Congress Genetics Applied to Livestock Production, Montpellier, France. 